\title{
Social aspects of dental caries in the context of mother-child pairs
}

\author{
Suzely Adas Saliba MOIMAZ1', Cristina Berger FADEL², Luiz Fernando LOLLI ${ }^{3}$, Cléa Adas Saliba GARBIN ${ }^{4}$ Artênio \\ José Ísper GARBIN ${ }^{4}$, Nemre Adas SALIBA ${ }^{1}$
}

1- Department of Pediatric and Social Dentistry, Univ. Estadual Paulista - UNESP, Araçatuba, SP, Brazil.
2- Department of Dentistry, Ponta Grossa State University - UEPG, Ponta Grossa, PR, Brazil.
3- Department of Dentistry, Ingá Unit of Higher Education - UNINGÁ, Maringá, PR, Brazil.
4- Department of Pediatric and Social Dentistry, Univ. Estadual Paulista - UNESP, Araçatuba, SP, Brazil.

Corresponding address: Cristina Berger Fadel - Rua Dr. Paula Xavier, 909, Ponta Grossa - PR - 84010-270 - Brazil - Phone: +55 4232203106 - Fax: +55 4232203104 - e-mail: cbfadel@gmail.com

Submitted: February 28, 2013 - Modification: September 4, 2013 - Accepted: November 26, 2013

\section{ABSTRACT}

\begin{abstract}
The relationship between mother and child in the context of oral health has traditionally been exposed by the scientific literature in microbiology, which lacks a broad and necessary discussion of health and illness seen as processes, both biological and social. Objective: Investigate the family social determinants associated with the caries history of children and the need for dental treatment (NDT) among their mothers was the objective of this study. Material and Methods: This research employed a cross-sectional study of mother-child pairs living in southern Brazil. Data collection occurred in public institutions of early childhood education. The instruments included a structured questionnaire administered to mothers and clinical oral examinations of the mothers and children. The social variables considered were marital status, maternal education, number of children, income, employment status, and frequency of visits to a dental professional. The measured outcomes were the maternal NDT and child caries history. Data were analyzed by the chi-square test $(x 2)$ and by discriminant analysis. Results: The final sample consisted of 272 mother-child pairs and it was found that the greatest need for treatment was among mothers with low educational level and low family income who rarely or never visited a dentist. Tooth decay was less frequent in only child, and most frequent in children of mothers with low educational attainment, and in children in lower income households who rarely or never visited the dentist. The social determinants of caries in children and of the maternal NDT were similar. It follows that the maternal NDT and caries history among children were strongly associated with maternal education $(p<0.0001)$, household income $(p<0.0001)$, and frequency of visits to a dental professional (0.0018). Caries history among children was also associated with number of children in the household $(p<0.0001)$. Conclusions: The results suggest that the caries experience in children depended less on the family social variables than on the maternal NDT.
\end{abstract}

Keywords: Social conditions. Risk factors. Dental caries. Oral health. Mother-child relations.

\section{INTRODUCTION}

Dental caries have been described as a social disease, as their formation is associated with biological, dietary, behavioral, and socioeconomic factors, as well as access to consumer goods and health services ${ }^{13}$. Although the prevalence and severity of dental caries has decreased among Brazilian children and adolescents in the last two decades, expanding preventive resources to reach all communities and social strata remains challenging ${ }^{2}$.

Numerous studies have addressed the correlation between oral health and social factors such as income, education, number of children, and other variables ${ }^{12,16,21,22,25,31}$. The national surveys conducted in Brazil in 2000 and 2010 showed that oral health is heterogenous, with differences found among regions and social groups. Socially deprived populations were at particular risk of severe dental 
disease ${ }^{5,6}$.

Social changes ultimately lead to changes within the family. Increasingly, women are considered as the reference person in the family. In this scenario, the mother assumes a central role in the formation, transmission, and environmental conservation and social development of other family members, especially her children ${ }^{24}$. It is therefore likely that the health of both the mother and child are similar or are linked to social determinants, given that they live in the same social context.

The purpose of the present study was to investigate the family social determinants associated with the caries history of children and the need for dental treatment (NDT) among their mothers.

\section{MATERIAL AND METHODS}

\section{Study design and sample population}

A cross-sectional study was performed among children (age: 1-5 years) enrolled in ten public schools in southern Brazil and their mothers. The initial design of this study was approved by the Ethics Committee of the Faculty of Dentistry of Araçatuba (FOA Case 2006-01460) in accordance with the Declaration of Helsinki. An initial probability sample of 360 individuals was selected to participate. A sample size calculation was performed using Epi Info 6.0 considering a range of $95 \%$ and a $5 \%$ margin of error over the total population size for the study. Because the numbers of children enrolled in each school proved to be very similar, the samples were not stratified according to this parameter. At the end of this process, 13 groups of children distributed among ten schools were selected. Each of the schools gave their consent to participate in this study.

\section{Data acquisition}

Data were collected by a single researcher, who was previously trained and standardized. The structured instrument used for this study was previously validated by a pilot study and it consists of three distinct parts. The first part addresses the family social characteristics, including the maternal education level, employment status, average monthly income, age, marital status, number of children, and frequency of visits to the dentist. The second part assesses the NDT of the mother (maternal NDT), according to the presence of dental caries determined by oral examination ${ }^{34}$. The third part assesses whether the child has a history of or has current untreated dental caries, based on oral examination.

Table 1- Association between socioeconomic status and need for dental treatment (NDT) in mothers of 272 children enrolled in public institutions of early childhood education in southern Brazil

\begin{tabular}{|c|c|c|c|c|c|c|}
\hline $\begin{array}{c}\text { Socioeconomic } \\
\text { variable }\end{array}$ & & $\begin{array}{c}\text { Mothers with } \\
\text { NDT }\end{array}$ & $\begin{array}{c}\text { Mothers with } \\
\text { NDT }(\%)\end{array}$ & $\begin{array}{c}\text { Mothers w/o } \\
\text { NDT }\end{array}$ & $\begin{array}{c}\text { Mothers w/o } \\
\text { NDT (\%) }\end{array}$ & p-value ** \\
\hline \multirow[t]{2}{*}{ Marital status } & Unmarried & 27 & $10 \%$ & 28 & $10 \%$ & 0.695 \\
\hline & Married & 117 & $43 \%$ & 100 & $37 \%$ & \\
\hline \multirow[t]{2}{*}{ No. of children } & 1 child & 102 & $38 \%$ & 96 & $35 \%$ & 0.404 \\
\hline & $>1$ child & 43 & $16 \%$ & 31 & $11 \%$ & \\
\hline \multirow[t]{4}{*}{ Education level } & Basic & 97 & $36 \%$ & 41 & $15 \%$ & $<0.0001$ \\
\hline & Fundamental & 34 & $13 \%$ & 7 & $3 \%$ & \\
\hline & High School & 14 & $5 \%$ & 75 & $28 \%$ & \\
\hline & Higher ed. & 0 & $0 \%$ & 4 & $1 \%$ & \\
\hline \multirow[t]{2}{*}{ Employment } & Yes & 141 & $52 \%$ & 119 & $44 \%$ & 0.261 \\
\hline & No & 4 & $1 \%$ & 8 & $3 \%$ & \\
\hline \multirow[t]{3}{*}{ Income } & $<\mathrm{BMMW}^{*}$ & 103 & $38 \%$ & 45 & $17 \%$ & $<0.0001$ \\
\hline & $1-3 \times$ BMMW* $^{*}$ & 42 & $15 \%$ & 31 & $11 \%$ & \\
\hline & $>3 \times$ BMMW $^{*}$ & 0 & $0 \%$ & 51 & $19 \%$ & \\
\hline \multirow{4}{*}{$\begin{array}{c}\text { Frequency of } \\
\text { visits to a dentist }\end{array}$} & Never & 79 & $29 \%$ & 44 & $16 \%$ & 0.0018 \\
\hline & Rarely & 52 & $19 \%$ & 64 & $24 \%$ & \\
\hline & $1 \times /$ year & 14 & $5 \%$ & 14 & $5 \%$ & \\
\hline & $>1 \times /$ year & 0 & $0 \%$ & 5 & $2 \%$ & \\
\hline
\end{tabular}

* Brazilian minimum monthly wage (BMMW) \$465.00 BRL (U.S. \$258.00)

${ }^{* *} \mathrm{X}^{2}$ test 
Oral examinations of the mother-child pairs were performed at the ten schools. Examinations were performed under artificial light, and included the use of exploratory probes, mirrors, clinical plans, wooden spatulas, and sterile pads.

The initial group of mother-child pairs was subdivided into four groups based on the oral examination results. Group 1 (G1) included pairs with a maternal NDT and a child with caries history. Group 2 (G2) included pairs with no maternal NDT and a child with caries history. Group 3 (G3) included pairs with a maternal NDT and a caries-free child. Group 4 (G4) included pairs with no maternal NDT and a caries-free child.

\section{Data analysis}

The diagnostic intra-rater concordance was determined by the Kappa test $(K=0.98)$. The association between categorical variables (marital status, number of children, maternal education level, employment status, income, and frequency of visits to the dentist) and the variables (maternal NDT and child caries history) was analyzed using the chi-square test $\left(X^{2}\right)$. Statistical significance was defined at the $5 \%$ level. Multivariate discriminant analysis (MDA) was performed for the four groups by assessing the proximity-distance space between them, considering all of the social variables together. All tests were performed using the statistical software BioStat 5.0.

\section{RESULTS}

The final sample consisted of 272 mother-child pairs. The loss of individuals from the sample was due to the refusal of mothers to participate $(n=67)$ or the absence of the child at the time of clinical examination $(n=57)$. Most of the mothers were married $(79.8 \%, n=217)$. In only 74 pairs $(27.2 \%)$, the child was the firstborn. Most mothers (50.7\%, $n=138$ ) had only basic education, emphasizing the low education of the population considered. Only 4 mothers $(1.5 \%)$ had completed higher education, $89(32.7 \%)$ had completed high school, and 41 $(15.1 \%)$ had completed primary education. The vast majority $(95.6 \% ; n=260)$ were currently employed, although the average family income was low. Of the 272 mother-child pairs, 148 (54.4\%) earned less than the Brazilian minimum monthly wage, $73(26.8 \%)$ earned $1-3 \times$ the minimum wage, and only $37(13.6 \%)$ earned $>3 \times$ the minimum wage. Mothers reported visiting a dental professional never $(45.2 \%, n=123)$, rarely $(42.6 \%$, $n=116)$, once a year $(10.3 \%, n=28)$, or more than

Table 2- Association between maternal socioeconomic variables and caries history of children enrolled in public institutions of early childhood education in southern Brazil

\begin{tabular}{|c|c|c|c|c|c|c|}
\hline $\begin{array}{c}\text { Socioeconomic } \\
\text { variable }\end{array}$ & & $\begin{array}{l}\text { Children wl } \\
\text { caries history }\end{array}$ & $\begin{array}{l}\text { Children wl } \\
\text { caries history } \\
(\%)\end{array}$ & $\begin{array}{l}\text { Children w/o } \\
\text { caries history }\end{array}$ & $\begin{array}{c}\text { Children w/o } \\
\text { caries history } \\
(\%)\end{array}$ & p-value** \\
\hline \multirow[t]{2}{*}{ Marital status } & Unmarried & 43 & $16 \%$ & 11 & $4 \%$ & 0.053 \\
\hline & Married & 141 & $52 \%$ & 77 & $28 \%$ & \\
\hline \multirow[t]{2}{*}{ No. of children } & 1 child & 120 & $44 \%$ & 78 & $29 \%$ & $<0.0001$ \\
\hline & $>1$ child & 64 & $24 \%$ & 10 & $4 \%$ & \\
\hline \multirow[t]{4}{*}{ Education level } & Basic & 138 & $51 \%$ & 0 & $0 \%$ & $<0.0001$ \\
\hline & Fundamental & 39 & $14 \%$ & 2 & $1 \%$ & \\
\hline & High school & 7 & $3 \%$ & 82 & $30 \%$ & \\
\hline & Higher ed. & 0 & $0 \%$ & 4 & $1 \%$ & \\
\hline \multirow[t]{2}{*}{ Employment } & Yes & 174 & $64 \%$ & 86 & $32 \%$ & 0.383 \\
\hline & No & 10 & $4 \%$ & 2 & $1 \%$ & \\
\hline \multirow[t]{3}{*}{ Income } & $<\mathrm{BMMW}^{*}$ & 148 & $54 \%$ & 0 & $0 \%$ & $<0.0001$ \\
\hline & $1-3 \times$ BMMW $^{*}$ & 36 & $13 \%$ & 37 & $14 \%$ & \\
\hline & $>3 \times \mathrm{BMMW}^{*}$ & 0 & $0 \%$ & 51 & $19 \%$ & \\
\hline \multirow{4}{*}{$\begin{array}{l}\text { Frequency of } \\
\text { visits to a dentist }\end{array}$} & Never & 113 & $42 \%$ & 10 & $4 \%$ & $<0.0001$ \\
\hline & Rarely & 55 & $20 \%$ & 61 & $22 \%$ & \\
\hline & $1 \times /$ year & 16 & $6 \%$ & 12 & $4 \%$ & \\
\hline & $>1 \times /$ year & 0 & $0 \%$ & 5 & $2 \%$ & \\
\hline
\end{tabular}

$\mathrm{N}=272$. Note: Brazilian minimum monthly wage (BMMW) $\$ 465.00$ BRL (U.S. \$258.00) 
once a year $(1.8 \%, \mathrm{n}=5)$.

We next examined the association between socioeconomic variables and the maternal NDT (Table 1 ) or the caries history of the child (Table 2 ). The maternal NDT was positively associated with low maternal educational attainment, a monthly household income of less than the minimum wage, and infrequent (never or rare) visits to the dentist. The caries history of children with a maternal NDT was positively associated with a lower family income, lower maternal educational attainment, low frequency of visiting a dentist (never or rarely), and a higher number of children in the family.

In order of frequency, the mother-child pairs largely belonged to G1 (49.9\%; maternal NDT and child caries history) or G4 (29.2\%; no maternal NDT and caries-free child), followed by G3 (18.0\%; no maternal NDT and child caries history) and distantly by G4 (3.6\%; maternal NDT and caries-free child) (Table 3).

Table 3- Distribution of the children in each of the four NDT groups

\begin{tabular}{ccc}
\hline Groups & $\mathbf{n}$ & $\%$ \\
\hline G1 & 134 & 49.2 \\
G2 & 49 & 18 \\
G3 & 10 & 3.6 \\
G4 & 79 & 29.2 \\
Total & 272 & 100 \\
\hline
\end{tabular}

Figure 1 shows the spatial relationship between the four groups. G1 and G2 were very close, G4 was more widespread, and G3 was substantially smaller and further away from the others. The finding indicates that all of the social variables must be evaluated together. G1 and G2 have greater similarity in their variables and these are more concentric. G4 has greater range in the variables, while the variables in G3 are very different from the others.

\section{DISCUSSION}

In the present study, it was found that the maternal NDT was associated with lower family income, maternal education level, and fewer visits to the dentist. Similar variables were also associated with the caries history of the children. Only child was less likely to have a history of caries. Moreover, the caries history of the child was less dependent on the social variables than on the maternal NDT, as children with or without caries were part of families with closer behavior.

The health conditions of a population, including oral health, are historically associated with social determinants. Several studies have identified an association between oral health and socioeconomic variables such as family income ${ }^{9,12,20}$, educational level ${ }^{12,22}$, delay and disruption of the education of the child ${ }^{7}$ and social class ${ }^{16,23,33}$, in various locations including Australia17, New Zealand ${ }^{28}$, Jordan $^{29}$, Japan $^{31}$, Sweden ${ }^{19}$, the UK ${ }^{10}$ and Brazil $8,11,27,30$.

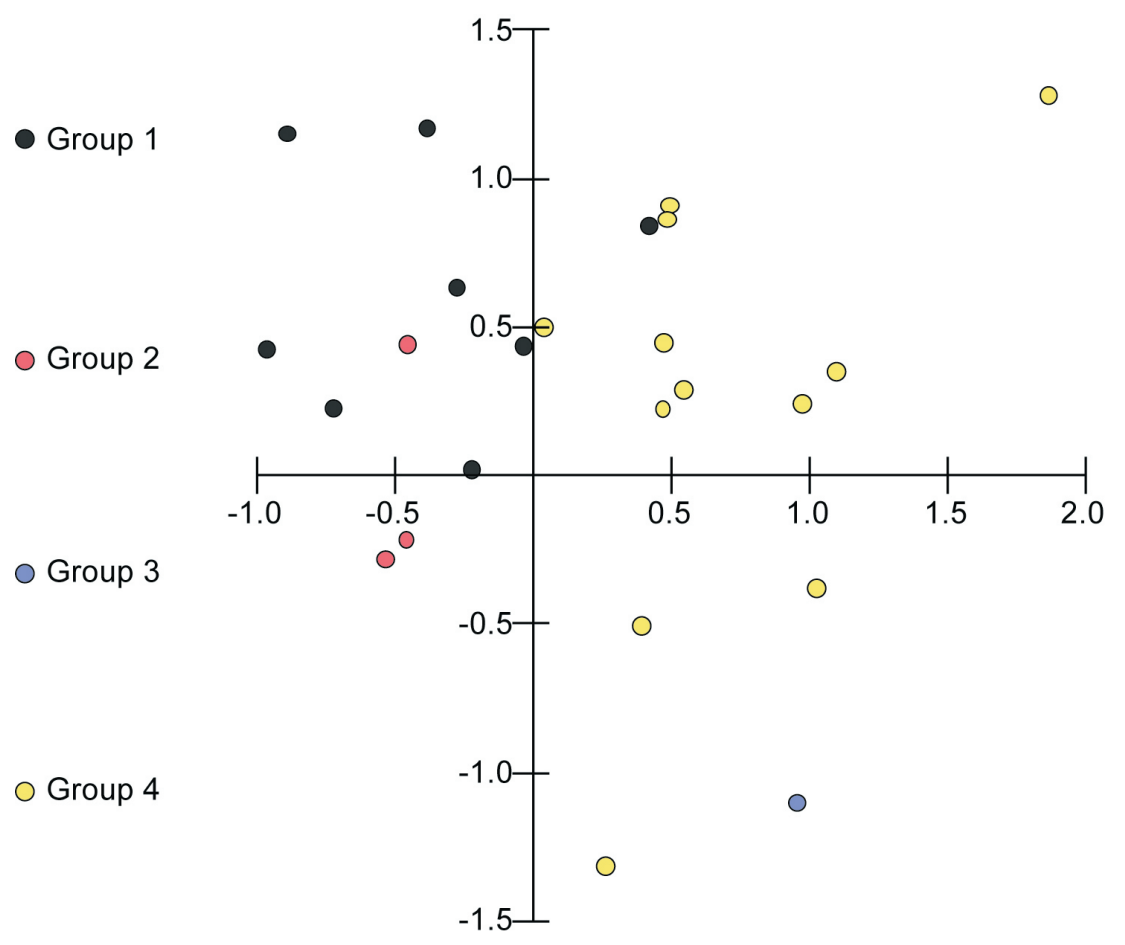

Figure 1- Spatial discrimination analysis of groups G1, G2, G3, and G4 according to the maternal need for dental treatment and the caries history of the child. Population sample is children attending public institutions of early childhood education in southern Brazil and their mothers 
It was observed that the maternal NDT was positively associated with low family income, low maternal education level, and infrequent visits to the dentist. The maternal NDT was not correlated with the number of children or the maternal marital or employment status. Interestingly, the child caries history was associated with the same variables as the maternal NDT, along with the number of children. Caries history was less likely in children who were the only child. The results of this study partly confirm the results of Galindo, et al. ${ }^{14}(2005)$, who demonstrated a relationship between the number of children and a higher rate of dental caries and maternal NDT. However, the number of children seems to be less important than the education level of the parents or the family income. Because the maternal NDT and child caries history were associated with the same variables, a relationship seems to exist between the oral health statuses of the mother and child. Fadel, et al. ${ }^{11}$ (2008) also suggested a strong relationship between the maternal NDT and the caries history of children in a previous survey conducted in southern Brazil.

Socioeconomic determinants of pediatric oral health have been examined by several previous researchers. Auad, et al. ${ }^{3}$ (2009), Peres, et al. ${ }^{26}$ (2005) and Borges, et al. ${ }^{4}$ (2012) examined populations of 12, 6 and 4-6 year old children, respectively, and showed that better family economic conditions and higher levels of maternal education were associated with fewer episodes of caries. Oliveira, et al. ${ }^{23}$ (2008) found that low maternal educational attainment $(<8$ years of schooling) and low family economic status were associated with increased incidence of dental caries in preschool children. Other determinants of oral health may also exist in addition to those tested here. In addition, in some regions the social determinants are less pervasive. A longitudinal study of risk factors for dental caries in infants in the United States identified only previous colonization by Streptococcus mutans and early consumption of sugars as risk factors. Social variables did not increase the caries risk ${ }^{32}$.

Among the mothers surveyed, 123 indicated that they had never consulted a dentist. The lack of access to dental care in this study was far greater than the Brazilian average for adults ${ }^{5}$. Goettems, et al. ${ }^{15}$ (2012), also in a cross-sectional study of 608 mother-child dyads, observed high association between irregular visits to a dentist by the mother and no dental visit by the child. The maternal oral health and number of visits to the dentist, which suggest barriers to oral health care access, are also reflections of socioeconomic conditions. Alexandre, et al. ${ }^{1}$ (2006) found that the need for dental treatment, represented specifically by toothache, was associated with absent routine dental care.
Preventive visits to the dentist and local availability of dentists have been shown to be crucial to caries prevention ${ }^{18}$.

While numerous studies have revealed an association between socioeconomic status and caries history or NDT, virtually no studies have demonstrated this association considering all socioeconomic variables together. In this study, when analyzing all of the social variables, it was found that the theoretically worst oral care condition (G1; maternal NDT and child with caries history) was in close proximity to $\mathrm{G} 2$ and was further away from $\mathrm{G} 3$ and $\mathrm{G} 4$. $\mathrm{G} 2$ was more inserted in the space of $\mathrm{G} 1$ and $\mathrm{G} 3$, indicating that $\mathrm{G} 1$ and $\mathrm{G} 2$ have greater similarity of social variables than $\mathrm{G} 1$ and G3. In other words, the NDT depended on larger social changes more than dental caries, because G3 (maternal NDT with non-caries child) was spatially further away.

\section{CONCLUSION}

The NDT in mother was associated with lower family income, low maternal education level and fewer visits to the dentist. Similarly, the variables income, maternal education and visits to the dentist were excessively associated with caries experience in this order. The only children presented less caries experience. Furthermore, the caries experience in child depends less from social oscillation than to maternal NDT, because the children with and without caries experience were part of families with closer social profiles.

\section{REFERENCES}

1- Alexandre GC, Nadanovsky P, Lopes CS, Faerstein E. Prevalence and factors associated with dental pain that prevents the performance of routine tasks by civil servants in Rio de Janeiro, Brazil. Cad Saude Publica. 2006;22:1073-8.

2-Antunes JL, Peres MA, Campos Mello TR, Waldman EA. Multilevel assessment of determinants of dental caries experience in Brazil. Community Dent Oral Epidemiol. 2006;34:146-52.

3- Auad SM, Waterhouse PJ, Nunn JH, Moynihan PJ. Dental caries and its association with sociodemographics, erosion, and diet in schoolchildren from southeast Brazil. Pediatr Dent. 2009;31:22935.

4- Borges HC, Garbín CA, Saliba O, Saliba NA, Moimaz SA. Socio-behavioral factors influence prevalence and severity of dental caries in children with primary dentition. Braz Oral Res. 2012;26(6):564-70.

5- Brazil, Ministry of Health. National Coordination of Oral Health. SB Brazil 2003 Project: oral health status of the population, 20022003 - main results. Brasilia: Ministry of Health; 2004.

6- Brazil, Ministry of Health. National Coordination of Oral Health. SB Brazil 2010 Project: oral health status of the population, 2010 - initial results. Brasilia: Ministry of Health; 2011.

7- Brodeur JM, Simard PL, Demers M, Contandriopoulos AP, Tessier G, Lepage $Y$, et al. Recruitment and compliance in school-based FMR programs. J Can Dent. Assoc. 1990;56:53-6. 
8- Cangussu MC, Castellanos RA, Pinheiro MF, Albuquerque SR, Pinho C. Dental caries in 12- and 15-year-old schoolchildren from public and private schools in Salvador, Bahia, Brazil, in 2001. Pesqui Odontol Bras. 2002;16:379-84.

9- Corrêa-Faria P, Martins-Júnior PA, Vieira-Andrade RG, Marques LS, Ramos-Jorge ML. Factors associated with the development of early childhood caries among Brazilian preschoolers. Braz Oral Res. 2013;27(4):356-62.

10- Ellwood RP, Davies GM, Worthington HV, Blinkhorn AS, Taylor GO, Davies RM. Relationship between area deprivation and the anticaries benefit of an oral health programme providing free fluoride toothpaste to young children. Community Dent Oral Epidemiol. 2004;32:159-65.

11- Fadel CB, Wagner DM, Furlan M. Association between maternal characteristics and social dental and dental caries in the child first dentition. J Dent Science. 2008;23:31-4.

12- Fracasso ML, Rios D, Provenzano MG, Goya S. Efficacy of an oral health promotion program for infants in the public sector. J Appl Oral Sci. 2005;13:372-6.

13- Frias AC, Antunes JLF, Junqueira SR, Narvai PC. Individual and contextual determinants of the prevalence of untreated caries in Brazil. Rev Panam Salud Publica. 2007;22:279-85.

14- Galindo EM, Pereira JA, Feliciano KV, Kovacs MH. Prevalence of caries and associated factors in children of the Vietnã Community, Recife. Rev Bras Saude Mater Infant. 2005;5:199-208.

15- Goettems ML, Ardenghi TM, Demarco FF, Romano AR, Torriani $D D$. Children's use of dental services: influence of maternal dental anxiety, attendance pattern, and perception of children's quality of life. Community Dent Oral Epidemiol. 2012;40(5):451-8.

16- Gushi LL, Soares MC, Forni TI, Vieira V, Wada RS, Sousa ML. Relationship between dental caries and socio-economic factors in adolescents. J Appl Oral Sci. 2005;13:305-11.

17- Hallett KB, O'Rourke PK. Social and behavioural determinants of early childhood caries. Aust Dent J. 2003;48:27-33.

18- Ismail AI, Sohn W, Lim S, Willem JM. Predictors of dental caries progression in primary teeth. J Dent Res. 2009;88:270-5. 19- Källestål C, Wall S. Socioeconomic effect on caries. Incidence among Swedish date 12-14-year-olds. Community Dent Oral Epidemiol. 2002;30:108-14.

20- Lopes RM, Domingues GG, Junqueira SR, Araujo ME, Frias AC. Conditional factors for untreated caries in 12-year-old children in the city of São Paulo. Braz Oral Res. 2013;27(4):376-81.

21- Moura LF, Moura MS, Toledo OA. Dental caries in children that participated in a dental program providing mother and child care. J Appl Oral Sci. 2006;14:53-60.
22- Nicolau B, Marcenes W, Hardy R, Sheiham A. A lifecourse approach to assess the social and psychological relationship between circumstances and gingival status in adolescents. J Clin Periodontol. 2003;30:1038-45.

23- Oliveira LB, Sheiham A, Bönecker M. Exploring the association of dental caries with social factors and nutritional status in Brazilian preschool children. Eur J Oral Sci. 2008;116:37-43.

24- Oliveira ML, Bastos AC. Health care practices in family context: a comparative case study. Psicol Reflex Crit. 2000;13:97-107.

25- Peres KG, Bastos JR, Latorre MR. Severity of dental caries in children and relationship with social and behavioral aspects. Rev Saude Publica. 2000;34:402-8.

26- Peres MA, Oliveira Latorre MR, Sheiham A, Peres KG, Barros $F C$, Hernandez PG, et al. Social and biological early life influences on severity of dental caries in children aged 6 years. Community Dent Oral Epidemiol. 2005;33:53-63.

27- Piovesan C, Antunes JL, Guedes RS, Ardenghi TM. Impact of socioeconomic and clinical factors on child oral health-related quality of life (COHRQoL). Qual Life Res. 2010;19:1359-66.

28- Poulton R, Caspi A, Milne BJ, Thomson WM, Taylor A, Sears MR, et al. Association between children's experience of socioeconomic disadvantage and adult health: a life-course study. Lancet. 2002;368:1640-5.

29- Sayegh A, Dini EL, Holt RD, Bedi R. Oral health, sociodemographic factors, dietary and oral hygiene practices in Jordanian children. J Dent. 2005;33:379-88.

30- Silveira Neto JM, Nadanovsky P. Social inequality in tooth extraction in a Brazilian insured working population. Community Dent Oral Epidemiol. 2007;35:331-6.

31- Tada A, Matsukubo T. Relationship between oral health behaviors and general health behaviors in a Japanese adult population. J Public Health Dent. 2003;63:250-4.

32- Warren JJ, Weber-Gasparoni K, Marshall TA, Drake DR, Dehkordi-Vakil M, Dawson DV, et al. A longitudinal study of dental caries risk among very young low SES children. Community Dent Oral Epidemiol. 2009;37:116-22.

33- Watt RG; Sheiham A. Integrating the common risk factor approach into a social determinants framework. Community Dent Oral Epidemiol. 2012;40:289-96.

34- World Health Organization. Oral health surveys: basic methods. $4^{\text {th }}$ ed. Geneva; WHO; 1997. 